\title{
Lactation and cardiovascular risk factors in mothers in a population-based study: the HUNT-study
}

\author{
Siv T Natland ${ }^{{ }^{*}}$, Tom I L Nilsen², Kristian Midthjell ${ }^{3}$, Lene F Andersen ${ }^{4}$ and Siri Forsmo ${ }^{1}$
}

\begin{abstract}
Background: Lactation has beneficial short term effects on maternal metabolic health, but the long term effects are less well known.

Methods: We studied the association between lifetime duration of lactation and cardiovascular risk factors in mothers later in life among 21,368 parous women aged 20 to 85 years attending the second Nord-Trøndelag Health Study (HUNT2) in 1995-1997, Norway, a cross-sectional population-based study. General linear modelling was used to calculate mean values of known cardiovascular risk factor levels in five categories of lifetime duration of lactation. Logistic regression was conducted to estimate odds ratios of hypertension, obesity and diabetes.

Results: Among women aged 50 years or younger, lifetime duration of lactation was significantly and inversely associated with body mass index ( $P$-trend, $<0.001)$, waist circumference $(P$-trend, $<0.001)$, systolic and diastolic blood pressure (both $P$-trends, $<0.001$ ), and serum levels of triglycerides, total cholesterol and low density lipoprotein cholesterol (all $P$-trends, $<0.001$ ) after adjustment for covariates. Parous women aged 50 years or younger who had never lactated had higher prevalence of hypertension, obesity and diabetes. In this age group, compared to women who had lactated for 24 months or more, parous women who had never lactated had an OR for hypertension of $1.88(95 \% \mathrm{Cl} 1.41,2.51)$, an OR for obesity of $3.37(95 \% \mathrm{Cl} 2.51,4.51)$ and an OR for diabetes of 5.87 ( $95 \% \mathrm{Cl} 2.25,15.3)$. Among women older than 50 years there were no clear associations.
\end{abstract}

Conclusion: Lifetime duration of lactation was associated with long term reduced cardiovascular risk levels in mothers aged 50 years or younger.

\section{Background}

Cardiovascular disease is the most common cause of death in women in the western world, and among its major modifiable risk factors are hypertension, dyslipidaemia, obesity and type 2-diabetes [1]. Lactation is a factor unique to women that may be associated with all these risk factors, and several studies have shown that it may affect them favourably [2-4]. Moreover, such advantages may persist several years post-weaning [5-13]. However, previous studies evaluating the association between lactation and maternal cardiovascular health have suffered from being short-term, having small sample sizes, or samples from selected populations or populations with

\footnotetext{
* Correspondence: siv.t.natland@ntnu.no

1 Department of Public Health and General Practice, Norwegian University of Science and Technology, PO Box 8904 MTFS, 7491 Trondheim, Norway Full list of author information is available at the end of the article
}

low breastfeeding rates. Norway has one of the highest breastfeeding rates in Europe, with $80 \%$ of the infants still being breastfed at six months [14]. We have therefore studied the association between lifetime duration of lactation and maternal cardiovascular risk factors later in life in a large unselected Norwegian population sample (about 35,000 women) in which breastfeeding was common and breastfeeding duration was long.

\section{Methods}

Study population

The Nord-Trøndelag Health Study (HUNT) is a population-based health survey aiming at the total adult population $>19$ years of age in the county of NordTrøndelag, Norway. Data collection and methods have been described in detail elsewhere [15]. Briefly, the second HUNT study (HUNT2) took place between 1995 and 
1997, and included two self-administered questionnaires and a clinical examination including standardised measurements of height, weight, waist circumference and blood pressure, as well as non-fasting measurements of blood glucose and serum lipids. The first questionnaire was sent by mail along with an invitation for a clinical examination. The questionnaire form included questions about general health and lifestyle, and the participants were requested to bring it to the physical examination. A second, more detailed questionnaire containing queries on number of live births and corresponding lactation history, as well as illnesses, medical treatment, lifestyle and socioeconomic factors was distributed during the examination, to be completed at home and returned by mail.

Among 47,312 women invited to HUNT2, a total of $35,280(75.5 \%)$ women participated. For this study, reasons for exclusions were non-response to the second questionnaire $(n=5,061)$, current pregnancy $(n=605)$, age $>85$ years $(n=343)$, non-attendance at the clinical examination $(n=355)$, self-report of infarction $(n=1)$, stroke $(n=9)$, angina $(n=12)$, diabetes prior to the first live birth $(n=43)$, less than one year since last child birth $(n=257)$ or unknown lactation history $(n=2206)$, leaving 26,388 women as eligible for the analyses, of whom 21,368 women had given birth to at least one child. For the analyses of blood pressure data we further excluded those who reported current or previous antihypertensive medication ( $\mathrm{n}=3061$ among parous women, $\mathrm{n}=682$ among nulliparous women). For the analyses of low density lipoprotein cholesterol we excluded those with triglyceride concentrations of $4.5 \mathrm{mmol} / \mathrm{L}$ or more ( $\mathrm{n}=321$ among parous women, $\mathrm{n}=78$ among nulliparous women).

\section{Lactation history}

Lactation history was self-reported by the women in the second questionnaire. For each live birth, the women reported the year of birth and corresponding lactation duration in whole months ("How many months did you breastfeed?"). Lifetime duration of lactation was calculated as the sum of lactation duration for all live births and categorised into five levels (none, 1-6, 7-12, 13-23, and $\geq 24$ months).

\section{Clinical measurements}

Height was measured without shoes to the nearest $1.0 \mathrm{~cm}$ and weight wearing light clothing to the nearest $0.5 \mathrm{~kg}$. Body mass index was calculated as weight $(\mathrm{kg})$ divided by the squared value of height $\left(\mathrm{m}^{2}\right)$. Waist circumferences were measured with a flexible steel band with the participants standing upright, and the numbers were rounded to the nearest $1.0 \mathrm{~cm}$. Waist circumference was measured horizontally at the height of the umbilicus [15].
Blood pressure was measured by specially trained nurses or technicians with oscillometric Dinamap 845 XT ( ${ }^{\circledR}$ Critikon, Tampa, FL) after adjustment of the cuff size according to the arm circumference. After an initial two minutes' rest, the blood pressure was automatically measured three times at intervals of one minute. In this study, we used the mean value of the second and third measurement of systolic and diastolic blood pressure.

The blood sample (non-fasting) drawn from all participants was centrifuged at the screening station and, on the same day, transported in a cooler to the laboratory. Serum lipids were analysed at the Central Laboratory, Levanger Hospital, Nord-Trøndelag Hospital Trust, using a Hitachi 911 Autoanalyser (Hitachi, Mito, Japan), applying reagents from Boehringer Mannheim (Mannheim, Germany). Total serum cholesterol, high density lipoprotein (HDL) cholesterol and triglycerides were measured by an enzymatic colorimetric method, and HDL cholesterol was measured after precipitation with phosphotungstate and magnesium ions. Glucose was measured using an enzymatic hexokinase method. The day-to-day coefficients of variation were $1.3-1.9 \%$ for total cholesterol, $2.4 \%$ for HDL-cholesterol, $0.7-1.3 \%$ for triglycerides and 1.3-2.0\% for glucose.

Low density lipoprotein (LDL) cholesterol was calculated using the Friedewald formula: LDL cholesterol=total serum cholesterol - HDL cholesterol - one-fifth of the triglyceride concentration [16]. LDL was only calculated in participants with triglyceride concentrations lower than $4.5 \mathrm{mmol} / \mathrm{L}$.

\section{Analyses}

In order to examine whether the effects of lactation duration were modified by age, we conducted analysis stratified by age ( $\leq 50$ years and $>50$ years) and also tested for statistical interaction by including a product term of lactation duration and age \pm 50 years in the regression model. We used a general linear model to calculate mean values of body mass index, waist circumference, systolic and diastolic blood pressure, serum lipid levels and blood glucose levels in five categories of lactation, and to estimate adjusted mean difference with $95 \%$ confidence intervals (CI) between the categories. Previous studies have shown beneficial maternal metabolic effects with increasing duration of lactation $[6,11,17]$. Hence, lifetime duration of lactation for $\geq 24$ months, the category with the longest lactation duration, was used as a reference category, as this was assumed to be the most beneficial lactation duration. Lipid and glucose concentrations were log-transformed due to non-normal distribution, and hence we calculated geometric means and crude and adjusted differences in percent between the categories for each lipid and for glucose. $P$-values for linear trend were calculated first across the five categories 
of lactation duration and then across four categories of lactation duration, excluding the 'never lactated' group, by treating the categories as an ordinal variable in the regression model. All associations were adjusted for potential confounding, with maternal age, education (primary school, secondary school, college/university and unknown), smoking status (current, former or never smoked), hours of physical activity per week (no activity, $<3$ hours light or $<1$ hour hard activity, $>3$ hours light or 1 hour hard activity, $>1$ hour hard activity, and unknown), marital status (unmarried, divorced, widowed and married/cohabiting) and parity (1, 2, 3 or $\geq 4$ children). In analyses of serum lipids and blood glucose we also adjusted for time since last meal. In supplementary analyses, we adjusted first for time since last birth, and then for body mass index. We also did the analyses described above comparing nulliparous and parous women.

In additional analyses, we used logistic regression to estimate crude and adjusted odds ratios (ORs) with 95\% CIs of hypertension ( $\geq 140 / 90 \mathrm{mmHg}$ or current antihypertensive treatment), obesity (body mass index $\geq 30 \mathrm{~kg} / \mathrm{m}^{2}$ ), and diabetes ('yes' versus 'no' to the question 'Do you have or have you had diabetes?' or blood glucose $\geq 11.1 \mathrm{mmol} / \mathrm{L}$ ) associated with five categories of lactation duration. We also did corresponding analyses comparing nulliparous and parous women.

All statistical tests were two-sided, and all analyses were performed using SPSS for Windows (version 16, SPSS Inc., Chicago; IL, USA).

\section{Ethical approval}

The study was approved by the Norwegian Regional Committees for Medical and Health Research Ethics and by the Norwegian Data Inspectorate. Informed consent was given by all participants in the HUNT-study.

\section{Results}

The parous women had a mean age of 50.4 years when attending HUNT2, they reported a median parity of two live births, a median lifetime duration of lactation of 13 months and time since the last delivery was on average 21.1 years (data not shown). The majority (96.7\%) of the 21,368 parous women had breastfed one or more children, and approximately one in five women $(21.4 \%)$ reported a lifetime duration of lactation longer than 24 months. Across the lactation categories, there were significant differences in maternal age, educational level, smoking status, the level of physical activity, marital status and parity in our study (Table 1). Furthermore, the variables that we a priori considered as confounders, namely: educational level, smoking status, level of physical activity, marital status and parity, were all associated with the outcome variables in our study (data not shown).
There was evidence of statistical interaction between age at participation ( \pm 50 years) and lactation duration for several of the outcome variables under study $(P$-values from interaction tests; $<0.001$ for $\mathrm{BMI} ;<0.001$ for waist circumference; 0.043 for systolic blood pressure; $<0.001$ for triglycerides; < 0.001 for total cholesterol, and 0.011 for HDL-cholesterol). Thus, the remainder of the analyses were stratified by age. Overall, there was an inverse association between lifetime duration of lactation and both body mass index $(P$-trend, $<0.001)$ and waist circumference $(P$-trend $=0.01)$ among women 50 years of age or younger (Table 2). After adjusting for potential confounders, women 50 years of age or younger who reported no lactation had a body mass index that was $2.5 \mathrm{~kg} / \mathrm{m}^{2}(95 \% \mathrm{CI}$ $2.0,3.0)$ higher and a waist circumference that was $5.3 \mathrm{~cm}$ (95\% CI 4.2, 6.5) wider than the reference group of women who had lactated $\geq 24$ months (Table 2). Adjusting for time since last birth did not change these estimates. Among women older than 50 years, there were no significant relations between duration of lactation and body mass index. However, women older than 50 years who reported no lactation had a waist circumference that was $1.5 \mathrm{~cm}$ wider than the reference group who had lactated $\geq 24$ months.

A similar pattern was observed in age-stratified analysis of systolic and diastolic blood pressure, shown in Figure 1. In multi-adjusted analysis, women 50 years of age or younger who had never lactated had $4.9 \mathrm{mmHg}$ (95\% CI 3.2, 6.6) higher systolic blood pressure and $2.9 \mathrm{mmHg}(95 \%$ CI 1.8, 4.1) higher diastolic blood pressure than women who had lactated $\geq 24$ months (both $P$-trends, < 0.001). Among women older than 50 years, there were no significant relationships between duration of lactation and systolic or diastolic blood pressure. Additional adjustment for body mass index and time since last birth attenuated the estimates of both systolic and diastolic blood pressure among women 50 years or younger, whereas the estimates among women older than 50 years remained largely similar (data not shown).

The analysis of lifetime duration of lactation and levels of triglycerides, total cholesterol and LDL-cholesterol also showed an inverse pattern and an apparent dose-response relationship (all $P$-trends, $<0.001$ ) among women 50 years or younger, whereas among women older than 50 years no significant associations were found. In analyses of logtransformed lipid values, women 50 years or younger who had never lactated had $17 \%$ (95\% CI 11, 24) higher triglyceride levels, 5\% (95\% CI 3, 7) higher total cholesterol levels and $8 \%(95 \% \mathrm{CI} 4,11)$ higher LDL-cholesterol levels than women who had lactated $\geq 24$ months (Table 3 ). Additional adjustments for time since last birth did not change these estimates, whereas additional adjustments for body mass index attenuated the estimates (data not shown). The results for HDL cholesterol showed a somewhat different 
Table 1 Characteristics of women in the HUNT2-study, Norway, 1995-97 (N=26,388)

\begin{tabular}{|c|c|c|c|c|c|c|}
\hline \multirow[b]{3}{*}{ Variables $^{a}$} & \multirow{3}{*}{$\begin{array}{l}\text { Nulliparous women } \\
n=5,020\end{array}$} & \multicolumn{5}{|c|}{ Parous women } \\
\hline & & \multicolumn{5}{|c|}{ Lifetime duration of lactation (months) } \\
\hline & & $\begin{array}{l}0 \\
n=705\end{array}$ & $\begin{array}{l}1-6 \\
n=4,421\end{array}$ & $\begin{array}{l}7-12 \\
n=5,401\end{array}$ & $\begin{array}{l}13-23 \\
n=6,266\end{array}$ & $\begin{array}{l}\geq 24 \\
n=4,575\end{array}$ \\
\hline Age, yrs, mean (SD) & $44.7(21.6)$ & $50.7(13.7)$ & $48.4(14.5)$ & $49.3(14.9)$ & $50.1(14.8)$ & $53.8(15.7)$ \\
\hline Age at delivery of first child, yrs, mean (SD) & - & $24.2(5.1)$ & $23.3(4.4)$ & $23.3(4.2)$ & $23.4(3.9)$ & $23.2(3.7)$ \\
\hline \multicolumn{7}{|l|}{ Parity, } \\
\hline Para 1 (\%) & - & 29.9 & 30.8 & 17.2 & 2.5 & 0.4 \\
\hline Para $2(\%)$ & - & 38.3 & 45.1 & 44.0 & 45.1 & 12.9 \\
\hline Para $3(\%)$ & - & 21.7 & 17.4 & 26.7 & 35.0 & 41.2 \\
\hline Para 4 or greater (\%) & - & 10.1 & 6.8 & 12.0 & 17.5 & 45.5 \\
\hline University/college education (\%) ${ }^{b}$ & 26.4 & 13.2 & 13.4 & 18.0 & 21.7 & 22.4 \\
\hline Never smoked (\%) & 62.2 & 37.3 & 36.7 & 45.7 & 50.9 & 60.5 \\
\hline High physical activity ${ }^{c, d}(\%)$ & 28.7 & 14.6 & 17.6 & 18.2 & 20.9 & 18.2 \\
\hline Unmarried/divorced (\%) & 61.6 & 24.4 & 28.7 & 23.2 & 16.5 & 11.1 \\
\hline Hypertension ${ }^{\mathrm{e}}(\%)$ & 37.5 & 47.2 & 36.3 & 37.5 & 37.5 & 44.9 \\
\hline Obesity $^{f}(\%)$ & 17.0 & 27.9 & 18.7 & 18.0 & 16.3 & 21.2 \\
\hline Diabetes $(\%)^{\mathrm{g}}$ & 3.0 & 4.4 & 1.9 & 2.0 & 2.4 & 3.7 \\
\hline
\end{tabular}

Abbreviation: SD, standard deviation.

${ }^{a}$ Continuous variables presented as mean (SD), categorical variables presented as $\%$ in each category of lactation.

${ }^{b}$ Number of women in the category unknown: $n=823$.

c High physical activity defined as $\geq 1$ hour hard physical activity per week.

${ }^{d}$ Number of women in the category unknown: $n=2,059$.

${ }^{\mathrm{e}}$ Hypertension defined as $\geq 140 / 90 \mathrm{mmHg}$ or current antihypertensive medication.

f Obesity defined as body mass index $\geq 30 \mathrm{~kg} / \mathrm{m}^{2}$.

${ }^{9}$ Diabetes defined as blood glucose $\geq 11.1 \mathrm{mmol} / \mathrm{L}$ or self reported diabetes in the questionnaire.

pattern. Women 50 years or younger who had never lactated had $4 \%(95 \%$ CI 1, 6) lower HDL cholesterol levels than women who had lactated $\geq 24$ months ( $P$-trend, 0.008). Additional adjustments for time since last birth did not change these estimates, whereas no associations remained after adjustments for body mass index. As in the analyses of the other serum lipids, there were no significant associations among women older than 50 years.

Contrary to blood pressure and serum lipids, there was no statistically significant linear trend across the lactation categories in blood glucose levels (Table 3) in either of the two age groups. However, in women 50 years or younger there was weak evidence of a dose-dependent association $(P$-trend, $=0.06)$, but no associations remained after additional adjustments for body mass index (data not shown).

Of the total study sample of parous women $(n=21,368)$, $39.0 \%$ of the women had hypertension, $18.7 \%$ were obese and $2.5 \%$ had known diabetes (Table 4). The corresponding prevalences among nulliparous women $(\mathrm{n}=5,020)$, were $37.5 \%, 17.0 \%$ and $3.0 \%$, respectively. Among women 50 years or younger, lifetime duration of lactation was inversely associated with the prevalence of hypertension ( $P$-trend, $<0.001)$, obesity $(P$-trend, $<0.001)$ and diabetes $(P$-trend, $=0.004)$. Parous women 50 years or younger who had never lactated had an almost doubled risk for hypertension, more than three times the risk of obesity and more than five times the risk of diabetes compared to women in the reference group who had lactated for $\geq 24$ months (Table 4). Among women older than 50 years no associations were found. Adjusting for time since last birth did not change these estimates, whereas adjusting for body mass index attenuated the estimates of both risk for hypertension and for diabetes (data not shown).

\section{Discussion}

In this large population-based study, we found that prolonged lifetime lactation was associated with a more favourable cardiovascular risk profile among women 50 years or younger. Parous women $\leq 50$ years who had never lactated were more likely to have developed hypertension, obesity and diabetes than women who had the longest lactation duration. Furthermore, there were strong indications of a dose-response association between the total duration of lactation and a favourable cardiovascular risk profile. Although the largest difference was found for women who had never lactated compared to those who had ever lactated, our analyses showed that the associations remained significant also within the lactation categories. Among women older than 50 years, only waist circumference and possibly diabetes were associated with lactation duration. 
Table 2 Body mass index and waist circumference in nulliparous and parous women $(\mathbf{n}=\mathbf{2 6 , 3 8 8})$

\begin{tabular}{|c|c|c|c|c|c|c|c|c|}
\hline & \multicolumn{4}{|c|}{ Women $\leq 50$ years of age $(n=14,677)$} & \multicolumn{4}{|c|}{ Women $>50$ years of age $(n=11,711)$} \\
\hline & No. & Crude mean & Adjusted mean $^{\mathrm{a}}$ & $95 \% \mathrm{Cl}$ & No. & Crude mean & Adjusted mean $^{a}$ & $95 \% \mathrm{Cl}$ \\
\hline \multicolumn{9}{|l|}{ BMI $\left(\mathrm{kg} / \mathrm{m}^{2}\right)$} \\
\hline Nulliparous women & 3,011 & 24.8 & 25.8 & $25.5,26.1$ & 2,009 & 27.3 & 26.9 & $26.6,27.1$ \\
\hline Parous women & 11,666 & 25.4 & 25.6 & $25.3,25.9$ & 9,702 & 27.5 & 27.3 & $27.1,27.5$ \\
\hline$P$-value & & & 0.026 & & & & $<0.001$ & \\
\hline \multicolumn{9}{|c|}{ Months of lifetime lactation } \\
\hline Never & 360 & 27.5 & 27.6 & $27.1,28.1$ & 345 & 27.7 & 27.7 & $27.2,28.3$ \\
\hline $1-6$ & 2,587 & 25.7 & 26.1 & $25.8,26.5$ & 1,834 & 27.1 & 27.2 & $26.9,27.6$ \\
\hline $7-12$ & 3,038 & 25.4 & 25.7 & $25.4,26.0$ & 2,363 & 27.2 & 27.2 & $26.9,27.5$ \\
\hline $13-23$ & 3,513 & 25.1 & 25.3 & $25.0,25.6$ & 2,753 & 27.4 & 27.3 & $27.0,27.6$ \\
\hline$\geq 24$ & 2,168 & 25.1 & 25.1 & $24.8,25.5$ & 2,407 & 28.2 & 27.6 & $27.2,27.9$ \\
\hline$P$ - trend $^{c}$ & & & $<0.001$ & & & & 0.542 & \\
\hline$P$ - trend $^{d}$ & & & $<0.001$ & & & & 0.675 & \\
\hline \multicolumn{9}{|c|}{ Waist cirmcumference $(\mathrm{cm})$} \\
\hline Nulliparous women & 3,012 & 76.1 & 79.2 & $78.5,80.0$ & 2,009 & 85.3 & 84.2 & $83.6,84.7$ \\
\hline Parous women & 11,919 & 78.8 & 79.3 & $78.6,80.0$ & 9,702 & 85.0 & 85.0 & $84.5,85.5$ \\
\hline$P$-value ${ }^{b}$ & & & 0.723 & & & & 0.004 & \\
\hline \multicolumn{9}{|c|}{ Months of lifetime lactation } \\
\hline Never & 360 & 83.4 & 83.9 & $82.6,85.2$ & 345 & 86.3 & 86.9 & $85.7,88.2$ \\
\hline $1-6$ & 2,587 & 79.5 & 80.5 & 79.7, 81.4 & 1,834 & 84.3 & 85.1 & $84.3,85.9$ \\
\hline $7-12$ & 3,038 & 78.8 & 79.7 & $78.9,80.5$ & 2,363 & 84.3 & 84.7 & $83.9,85.5$ \\
\hline $13-23$ & 3,513 & 78.1 & 78.9 & $78.1,79.8$ & 2,753 & 84.4 & 84.6 & $83.8,85.4$ \\
\hline$\geq 23$ & 2,168 & 78.4 & 78.6 & $77.7,79.4$ & 2,407 & 86.8 & 85.4 & $84.5,86.2$ \\
\hline$P$ - trend ${ }^{c}$ & & & $<0.001$ & & & & 0.03 & \\
\hline$P$ - trend $^{\mathrm{d}}$ & & & $<0.001$ & & & & 0.085 & \\
\hline
\end{tabular}

Abbreviations: No, number; $\mathrm{Cl}$, confidence interval; $\mathrm{BMI}$, body mass index.

${ }^{a}$ For nulliparous women: Adjusted for maternal age, smoking status, physical activity, education and marital status. For parous women: Adjusted for maternal age, smoking status, physical activity, education, marital status and parity.

${ }^{\mathrm{b}} P$-value between nulliparous vs parous women. Adjusted for maternal age, smoking status, physical activity, education and marital status.

' $P$-trend across all five categories of lifetime lactation duration, including the category "never".

" $P$-trend across four categories of lifetime lactation duration, excluding the category "never".

Our findings are consistent with recent studies showing that the favourable effects of lactation on maternal metabolic health persist post weaning [7,8,11,17-20] and thereby further supporting the notion that lactation may induce long-term beneficial effects on maternal blood pressure, weight [21], diabetes $[6,18]$, components of the metabolic syndrome [5,19] and cardiovascular health $[7,11,17]$. Previous studies have shown that the beneficial effect of lactation on cardiovascular risk factors seems to wane with time since last birth $[6,11,18]$. Adjusting for this period did not change the estimate in our study. On the other hand, the stronger associations observed among women aged $\leq 50$ years compared to those aged $>50$ years could possibly be due to the shorter period since last birth.

The present study was conducted in a large and unselected population with a wide age range and a high participation rate. Breastfeeding was common, and this observation is consistent with other studies showing that breastfeeding rates in Norway are among the highest in industrialised countries [22]. We therefore have a large sample size of women who have lactated. Combined with the standardised measurements of lipids, anthropometric measures and blood pressure, it provides a unique opportunity to study the association of lactation and cardiovascular risk factors and whether differences exist by duration of lactation.

However, the cross sectional study design calls for a cautious interpretation of the findings, as in all observational studies. It is possible that women who breastfeed their children have a better health status, healthier lifestyles and higher socioeconomic status than women who do not breastfeed [23]. Given the high rates of breastfeeding among Norwegian women, the group of women who had never lactated in our study was less than $4 \%$ of 
the entire sample. Thus, it is possible that the group of women who had never lactated in our study differed in major confounders than might be expected in populations where breastfeeding rates are lower.

A previous study among Norwegian women found that maternal age, education and smoking were among the most important factors associated with lactation duration [22]. In addition to these factors, we found significant differences across the lactation categories in the level of physical activity, marital status, and parity in our study. Although all of these factors are known to be associated with risk of cardiovascular disease, adjusting for them did not materially change the estimated associations. However, residual confounding due to unmeasured and unknown factors cannot be ruled out, such as prepregnancy and early postpartum health status. Women with gestational diabetes mellitus are at an increased risk of developing type 2 diabetes [24]. Furthermore, gestational diabetes mellitus may have a role in impacting breastfeeding initiation and success, and could thus act as a major confounder. In a recent study, longer duration of lactation was associated with lower incidence of the metabolic syndrome both among women with and without a history of gestational diabetes mellitus, and the findings were particularly striking for women who developed gestational diabetes mellitus during their pregnancy [10]. In our study, women reporting a diagnosis of diabetes prior to first pregnancy were excluded from our analyses. Nevertheless, the lack of data on the history of gestational diabetes mellitus during pregnancy is a limitation of our study.

Moreover, the potential for reverse causation must be considered when interpreting the results from the present study. Obesity [25,26] and type 1 diabetes [27] have been linked to difficulties with lactation, and hence shorter lactation duration could be a marker for an already existing abnormal metabolic profile influencing whether the women lactate and for how long. Unfortunately, we did not have pre-pregnancy measurements of weight and height and could therefore not adjust for pre-pregnant body mass index. However, when we adjusted for body mass index measured at study participation in supplementary analyses, 
Table 3 Triglycerides, total-, HDL- and LDL-cholesterol and blood glucose (log-transformed) in nulliparous and parous women $(n=26,388)$

\begin{tabular}{|c|c|c|c|}
\hline \multicolumn{4}{|c|}{ Women $\leq 50$ years of age $(n=14,677)$} \\
\hline No. & $\begin{array}{l}\text { Crude } \\
\text { geometric mean }\end{array}$ & $\begin{array}{l}\text { Adjusted } \\
\text { geometric mean }\end{array}$ & $95 \% \mathrm{Cl}$ \\
\hline
\end{tabular}

Women $>50$ years of age $(n=11,711)$

No. Crude Adjusted

geometric mean

geometric mean $^{\mathrm{a}}$

Triglycerides (mmol/L)

Parous women $\quad 11,666 \quad 1.14$

1.21

1.16

$1.17,1.26 \quad 2,009 \quad 1.66$

$1.12,1.20 \quad 9,702 \quad 1.63$

1.58

1.63

0.02

$P$-value

$<0.001$

Months of lifetime lactation

$\begin{array}{lll}\text { Never } & 360 & 1.34\end{array}$

$1-6 \quad 2,587 \quad 1.22$

1.30

1.22

$7-12$

$3,038 \quad 1.15$

1.17

$13-23$

$3,513 \quad 1.11$

$\geq 24$

$2,168 \quad 1.08$

P- trend $^{c}$

\subsection{4}

1.11

$<0.001$

$<0.001$

$P$ - trend $^{\mathrm{d}}$

\section{Cholesterol ( $\mathrm{mmol} / \mathrm{L})$}

Nulliparous women 3,011 4.95

5.35

5.19

$<0.001$

$P$-value ${ }^{b}$

$11,666 \quad 5.27$

Months of lifetime lactation

Never $\quad 360 \quad 5.56$

$\begin{array}{lll}1-6 & 2,587 & 5.38\end{array}$

$7-12$

$3,038 \quad 5.28$

$13-23$

$3,513 \quad 5.20$

$\geq 24$

$2,168 \quad 5.17$

$P$ - trend $^{c}$

$P$ - trend $^{\mathrm{d}}$

HDL-cholesterol (mmol/L)

Nulliparous women $\quad 3,011 \quad 1.47$

$\begin{array}{lll}\text { Parous women } \quad 11,666 & 1.44\end{array}$

$P$-value ${ }^{b}$

$\begin{array}{lll}11,666 & 1.44 & 1.42\end{array}$

Months of lifetime lactation

Never $\quad 360 \quad 1.39$

$\begin{array}{lll}1-6 & 2,587 & 1.41\end{array}$

$7-12$

$3,038 \quad 1.44$

$13-23$

$\geq 24$

$3,513 \quad 1.45$

$P$ - trend $^{c}$

$2,168 \quad 1.45$

$P$ - trend $^{\mathrm{d}}$

LDL-cholesterol $^{\mathrm{e}}$ ( $\left.\mathrm{mmol} / \mathrm{L}\right)$

Nulliparous women 2999

Parous women

$11,576 \quad 3.48$

P-value
$<0.001$

\subsection{7 \\ 5.37 \\ 5.31 \\ 5.23 \\ 5.20 \\ $<0.001$ \\ $<0.001$}

\subsection{8}

1.38

1.43

1.44

1.43

0.008

0.06

3.49

3.43

0.006

$\begin{array}{lll}1.22,1.38 & 345 & 1.64 \\ 1.17,1.27 & 1,834 & 1.55 \\ 1.13,1.22 & 2,363 & 1.59 \\ 1.10,1.19 & 2,753 & 1.64 \\ 1.07,1.16 & 2,407 & 1.70\end{array}$

1.70

1.61

1.63

1.65

1.63

0.890

0.462

6.56

6.50

0.06

6.47

$5.35,5.59 \quad 345 \quad 6.48$

5.29, $5.45 \quad 1,834 \quad 6.52$

$5.23,5.39 \quad 2,363 \quad 6.54$

5.16, $5.31 \quad 2,753 \quad 6.61$

$5.12,5.28 \quad 2,407 \quad 6.62$

6.51

6.52

6.58

6.51

0.362

0.552

$1.46,1.51 \quad 2009 \quad 1.47$

1.50

$1.39,1.44 \quad 9702 \quad 1.46$

1.45

$<0.001$

1.44

1.34. $1.43 \quad 345 \quad 1.46$

1.39. $1.44 \quad 1,834 \quad 1.48$

1.40. $1.46 \quad 2,363 \quad 1.47$

1.41. $1.47 \quad 2,753 \quad 1.46$

1.40. $1.47 \quad 2,407 \quad 1.41$

1.45

1.45

1.45

1.43

0.362

0.265

4.58

4.57

0.661
$6.33,6.61$

$1.48,1.52$

1.39. 1.48

$4.52,4.65$

$1.61,1.80$

$1.55,1.67$

$1.57,1.68$

$1.59,1.70$

$1.57,1.69$

$6.50,6.63$

$6.45,6.55$

$6.42,6.59$

$6.43,6.60$

$6.49,6.66$

$6.42,6.60$

$1.43,1.46$

1.42. 1.48

1.42. 1.48

1.42. 1.48

1.40. 1.46

$4.52,4.62$
$3.37,3.49 \quad 9471 \quad 4.64$

. 
Table 3 Triglycerides, total-, HDL- and LDL-cholesterol and blood glucose (log-transformed) in nulliparous and parous women ( $n=26,388)$ (Continued)

\begin{tabular}{|c|c|c|c|c|c|c|c|c|}
\hline \multicolumn{9}{|c|}{ Months of lifetime lactation } \\
\hline Never & 353 & 3.77 & 3.70 & $3.58,3.83$ & 337 & 4.55 & 4.55 & $4.42,4.69$ \\
\hline $1-6$ & 2,564 & 3.60 & 3.60 & $3.52,3.68$ & 1,798 & 4.57 & 4.57 & $4.49,4.66$ \\
\hline $7-12$ & 3,021 & 3.49 & 3.53 & $3.46,3.61$ & 2,316 & 4.58 & 4.58 & $4.50,4.67$ \\
\hline $13-23$ & 3,482 & 3.41 & 3.45 & $3.38,3.53$ & 2,677 & 4.64 & 4.64 & $4.55,4.72$ \\
\hline$\geq 24$ & 2,156 & 3.40 & 3.44 & $3.36,3.52$ & 2,343 & 4.58 & 4.58 & $4.49,4.67$ \\
\hline$P$ - trend $^{c}$ & & & $<0.001$ & & & & 0.396 & \\
\hline$P$ - trend $^{d}$ & & & $<0.001$ & & & & 0.509 & \\
\hline \multicolumn{9}{|l|}{ Glucose (mmol/L) } \\
\hline Nulliparous women & 3,011 & 4.93 & 5.10 & $5.04,5.16$ & 2,009 & 5.61 & 5.52 & $5.46,5.59$ \\
\hline Parous women & 11,666 & 5.02 & 4.99 & $4.94,5.04$ & 9,702 & 5.53 & 5.57 & $5.52,5.62$ \\
\hline$P$-value ${ }^{b}$ & & & $<0.001$ & & & & 0.183 & \\
\hline \multicolumn{9}{|c|}{ Months of lifetime lactation } \\
\hline Never & 360 & 5.15 & 5.10 & $5.00,5.20$ & 345 & 5.51 & 5.62 & $5.48,5.76$ \\
\hline $1-6$ & 2,587 & 5.04 & 5.02 & $4.96,5.09$ & 1,834 & 5.43 & 5.53 & $5.44,5.62$ \\
\hline $7-12$ & 3,038 & 5.01 & 5.00 & $4.94,5.06$ & 2,363 & 5.51 & 5.58 & $5.49,5.66$ \\
\hline $13-23$ & 3,513 & 5.02 & 5.00 & $4.94,5.07$ & 2,753 & 5.54 & 5.59 & $5.50,5.67$ \\
\hline$\geq 24$ & 2,168 & 5.01 & 4.99 & $4.92,5.06$ & 2,407 & 5.60 & 5.57 & $5.48,5.66$ \\
\hline$P$ - trend ${ }^{c}$ & & & 0.06 & & & & 0.587 & \\
\hline$P$ - trend $^{d}$ & & & 0.232 & & & & 0.268 & \\
\hline
\end{tabular}

Abbreviations: No. number; $\mathrm{Cl}$, confidence interval; HDL, high density lipoprotein; LDL, low density lipoprotein.

${ }^{a}$ For nulliparous women: Adjusted for maternal age, smoking status, physical activity, education, marital status and time since last meal. For parous women:

Adjusted for maternal age, smoking status, physical activity, education, marital status, time since last meal and parity.

b $P$-value between nulliparous vs parous. Adjusted for maternal age, smoking status, physical activity, education, marital status and time since last meal.

' $P$-trend across all five categories of lifetime lactation duration, including the category "never".

d $P$-trend across four categories of lifetime lactation duration, excluding the category "never".

e $\mathrm{LDL}$ was calculated only if serum triglycerides were lower than $4.5 \mathrm{mmol} / \mathrm{L}$.

the adjustments did not change our estimated associations substantially, with the exception of HDL-cholesterol. Obesity may either precede [26] or follow lactation practices. Thus, one may argue that body mass index measured at study participation rather acts as an intermediate factor, and hence should not be adjusted for as a confounder in the analyses.

Diet accounts for much of the variation in coronary heart disease risk [28]. The HUNT2 study was not designed to measure dietary intake, and we had insufficient dietary data to adjust for dietary factors in our analyses. However, previous studies have found that the association between lactation and cardiovascular health persists even after adjustment for dietary intake $[5,7,11,17]$.

Another limitation of the study is the lack of data on lactation intensity. Higher intensity of lactation has been associated with improved fasting glucose and lower insulin levels at 6-9 weeks postpartum in a previous study [29]. Data on lactation intensity could therefore possibly have strengthened our estimates of associations among women with higher, and attenuated the associations among women with lower, lactation intensity. Moreover, lactation was assessed retrospectively. Nevertheless, studies have shown that maternal recall of lactation is fairly valid and reliable [30], even after 20 years [31]. However, even if misclassification should exist, it is not likely to be differential according to cardiovascular risk factors. Our observed estimates are therefore likely to be conservative.

Furthermore, selection bias could have influenced our results. However, a non-responder study showed that the most important reason for non-attending the HUNT2study in the age group 20-69 was lack of time/moved away, while in those aged 70 years or more, immobilising and frequent follow-up by medical doctor were important reasons [32]. We do not believe that reasons for nonattending were unevenly distributed across the lactation categories, and we find it unlikely that selection bias would have altered the results in our study.

During pregnancy the maternal metabolism is profoundly changed, and the changes that occur could theoretically increase women's risk of metabolic disease. These changes include accumulation of adipose tissue 
Table 4 Odds ratio for hypertension, obesity and diabetes in nulliparous and parous women $(n=26,388)$

\begin{tabular}{|c|c|c|c|c|c|c|c|c|c|c|}
\hline \multirow{3}{*}{ Hypertension $^{\mathbf{b}}$} & \multicolumn{5}{|c|}{ Women $\leq 50$ years of age $(n=14,677)$} & \multicolumn{5}{|c|}{ Women $>50$ years of age $(n=11,711)$} \\
\hline & & & Crude OR & Adjusted $\mathrm{OR}^{\mathrm{a}}$ & $95 \% \mathrm{Cl}$ & & & Crude OR & Adjusted $O^{a}$ & $95 \% \mathrm{Cl}$ \\
\hline & No. & $\begin{array}{l}\text { No. } \\
\text { hypertension }\end{array}$ & & & & No. & $\begin{array}{l}\text { No. } \\
\text { hypertension }\end{array}$ & & & \\
\hline Nulliparous women & 3,011 & 367 & 1.0 (Ref.) & 1.0 (Ref.) & & 2,009 & 1,514 & 1.0 (Ref.) & 1.0 (Ref.) & \\
\hline Parous women & 11,666 & 2,006 & 1.49 & 0.75 & $0.65,0.89$ & 9,702 & 6,331 & 0.61 & 0.88 & $0.77,1.00$ \\
\hline$P$-value & & & & $<0.001$ & & & & & 0.05 & \\
\hline \multicolumn{11}{|c|}{ Months of lifetime lactation } \\
\hline Never & 360 & 98 & 2.08 & 1.88 & $1.41,2.51$ & 345 & 110 & 0.85 & 1.26 & $0.96,1.65$ \\
\hline $1-6$ & 2,587 & 489 & 1.29 & 1.24 & $1.03,1.49$ & 1,834 & 719 & 0.61 & 0.88 & $0.75,1.02$ \\
\hline $7-12$ & 3,038 & 528 & 1.17 & 1.16 & $0.98,1.37$ & 2,363 & 864 & 0.69 & 0.93 & $0.80,1.07$ \\
\hline $13-23$ & 3,513 & 560 & 1.05 & 1.03 & $0.88,1.21$ & 2,753 & 996 & 0.70 & 0.89 & $0.78,1.01$ \\
\hline$\geq 24$ & 2,168 & 331 & 1.0 (Ref.) & 1.0 (Ref.) & & 2,407 & 682 & 1.0 (Ref.) & 1.0 (Ref.) & \\
\hline$P$ - trend ${ }^{c}$ & & & & $<0.001$ & & & & & 0.944 & \\
\hline$P$ - trend $^{d}$ & & & & 0.009 & & & & & 0.218 & \\
\hline Obesity ${ }^{e}$ & No. & No. obesity & & & & No. & No. obesity & & & \\
\hline Nulliparous women & 3,011 & 357 & 1.0 (Ref.) & 1.0 (Ref.) & & 2,009 & 497 & 1.0 (Ref.) & 1.0 (Ref.) & \\
\hline Parous women & 11,666 & 1,501 & 1.10 & 0.82 & $0.70,0.96$ & 9,702 & 2490 & 1.05 & 1.26 & $1.11,1.43$ \\
\hline$P$-value & & & & 0.013 & & & & & $<0.001$ & \\
\hline \multicolumn{11}{|c|}{ Months of lifetime lactation } \\
\hline Never & 360 & 100 & 3.29 & 3.37 & $2.51,4.51$ & 345 & 97 & 0.87 & 1.17 & $0.89,1.53$ \\
\hline $1-6$ & 2,587 & 398 & 1.56 & 1.68 & $1.36,2.06$ & 1,834 & 429 & 0.68 & 0.92 & $0.79,1.09$ \\
\hline $7-12$ & 3,038 & 420 & 1.37 & 1.46 & $1.21,1.77$ & 2,363 & 552 & 0.68 & 0.88 & $0.76,1.01$ \\
\hline $13-23$ & 3,513 & 356 & 0.96 & 1.02 & $0.85,1.23$ & 2,753 & 668 & 0.72 & 0.89 & $0.78,1.01$ \\
\hline$\geq 24$ & 2,168 & 227 & 1.0 (Ref.) & 1.0 (Ref.) & & 2,407 & 744 & 1.0 (Ref.) & 1.0 (Ref.) & \\
\hline$P$ - trend $^{c}$ & & & & $<0.001$ & & & & & 0.861 & \\
\hline$P$ - trend $^{d}$ & & & & $<0.001$ & & & & & 0.457 & \\
\hline Diabetes $^{f}$ & No. & No. diabetes & & & & No. & No. diabetes & & & \\
\hline Nulliparous women & 3011 & 20 & 1.0 (Ref.) & 1.0 (Ref.) & & 2009 & 129 & 1.0 (Ref.) & 1.0 (Ref.) & \\
\hline Parous women & 11666 & 77 & 0.99 & 0.59 & $0.32,1.11$ & 9702 & 466 & 0.74 & 1.01 & $0.80,1.26$ \\
\hline$P$-value & & & & 0.102 & & & & & 0.957 & \\
\hline \multicolumn{11}{|c|}{ Months of lifetime lactation } \\
\hline Never & 360 & 10 & 5.60 & 5.87 & $2.25,15.3$ & 345 & 21 & 0.71 & 1.29 & $0.78,2.14$ \\
\hline $1-6$ & 2587 & 18 & 1.37 & 1.49 & $0.63,3.53$ & 1834 & 64 & 0.57 & 0.71 & $0.50,1.01$ \\
\hline $7-12$ & 3038 & 19 & 1.23 & 1.29 & $0.57,2.89$ & 2363 & 91 & 0.51 & 0.74 & $0.55,1.00$ \\
\hline $13-23$ & 3513 & 19 & 1.07 & 1.06 & $0.48,2.33$ & 2753 & 131 & 0.92 & 0.89 & $0.69,1.16$ \\
\hline$\geq 24$ & 2168 & 11 & 1.0 (Ref.) & 1.0 (Ref.) & & 2407 & 159 & 1.0 (Ref.) & 1.0 (Ref.) & \\
\hline$P$ - trend $^{c}$ & & & & 0.004 & & & & & 0.202 & \\
\hline$P$ - trend $^{d}$ & & & & 0.292 & & & & & 0.014 & \\
\hline
\end{tabular}

Abbreviations: No, number; OR, odds ratio; $\mathrm{Cl}$, confidence interval, Ref., reference category.

${ }^{a}$ Adjusted for maternal age, smoking status, physical activity, education and marital status. For parous women: maternal age, smoking status, physical activity, education, marital status and parity.

${ }^{b}$ Hypertension defined as $\geq 140 / 90 \mathrm{mmHg}$ or current antihypertensive treatment.

' $P$-trend across all five categories of lifetime lactation duration, including the category "never".

" $P$-trend across four categories of lifetime lactation duration, excluding the category "never".

eObesity defined as $\mathrm{BMI} \geq 30 \mathrm{~kg} / \mathrm{m}$.

fDiabetes defined as blood glucose $\geq 11.1 \mathrm{mmol} / \mathrm{L}$ or self reported diabetes in the questionnaire. 
stores [33], increased insulin resistance [34] and blood pressure, [35] as well as a change of the quantity and quality of circulating lipoproteins [36,37]. By the end of the pregnancy, LDL cholesterol and triglyceride levels are two to three times higher compared with prepregnancy levels. In fact, some studies have shown that increasing parity may increase risk of cardiovascular disease $[38,39]$. These studies do not, however, include data on lactation. Our findings of a more favourable cardiovascular risk profile associated with lactation seem to confirm the recent suggestion that lactation could affect risk of metabolic disease by facilitating a faster resetting of the maternal metabolism after pregnancy [40].

Lactation increases a mother's metabolic expenditure by an estimated $480 \mathrm{kcal} / \mathrm{d}$ [41], and although the association between lactation and postpartum weight loss so far remains inconclusive [21,42-45], lactation could reduce cardiovascular risk by mobilising accumulated fat stores. Furthermore, lactation provides a route for physiologic excretion of large amounts of cholesterol, which could explain the more speedy return of blood lipids to prepregnancy levels observed in lactating mothers [3]. Additionally, hormonal effects, such as those of prolactin and oxytocin, may affect maternal blood pressure [46]. Our data among women with an average time since last pregnancy of about 21 years suggest that these favourable changes are persisting on a long term scale and are not limited to the period of lactation. Among women older than 50 years, however, we found no similar linear trend in the association between lifetime duration of lactation and cardiovascular risk factors as in younger women. Still, women $>50$ years who had never lactated had a significantly higher body mass index, wider waist circumference, higher lipid and glucose levels and higher prevalence of hypertension, obesity and diabetes compared to women who had lactated. Menopause appears to be a time of transition to increased cardiovascular risk, including adverse changes in serum lipid profile [47]. Hence, the cardiovascular risk alterations occurring during the menopausal transition may dilute the possible beneficial effects of lactation on maternal metabolic health as shown in previous studies $[6,11,18]$.

Lactation may also improve insulin sensitivity and glucose tolerance. Insulin levels and insulin/glucose ratios are lower, and carbohydrate use and total energy expenditure are higher, in the lactating women compared to women who do not lactate [41]. Our data suggest a relation between lactation and glucose levels later in life. However, no statistically significant association with lifetime duration of lactation could be found in either age group, although the association among women 50 years or younger were close to significant. In contrast, the association between lifetime duration of lactation and the prevalence of diabetes was strong and significant in the younger age group, although not among the older women, further supporting the notion that the possible effect wanes with time since last delivery. These mechanisms, together with our results, indicate that lactation helps women return to pre-pregnant metabolism more quickly post partum, which could in turn affect metabolic disease risk profile later in life.

Our results indicate that lactation may have a considerable impact on cardiovascular risk factors. The difference in systolic/diastolic blood pressure between women 50 years or younger who had never lactated and women who had lactated for 24 months or more is similar to the blood pressure-lowering effect of salt reduction $(4 / 2 \mathrm{~mm} \mathrm{Hg})$ among normotensive individuals [48]. Furthermore, it has been estimated that a $10 \%$ reduction in serum cholesterol could halve the risk of ischaemic heart disease at age 40 [49], and hence the $5 \%$ difference in total cholesterol levels observed between women 50 years or younger who had never lactated, and women who had lactated more than 24 months, could represent a substantial risk reduction. Also, the $17 \%$ difference in triglycerides between women 50 years or younger who had never lactated and women who had lactated 24 months or more must be added to this altered cardiovascular disease risk pattern.

\section{Conclusions}

In conclusion, this large population-based study showed that lactation is associated with a more favourable cardiovascular risk profile in mothers later in life, and that the beneficial effects are most prominent among women 50 years or younger. Lactation may hence reduce the adverse pregnancy-related changes in cardiovascular risk factors, with effects lasting even beyond the childbearing years. If the observed associations are causal, lactation could have substantial potential for reducing women's risk of cardiovascular disease. Additional studies are needed to confirm the observed protective associations and their underlying mechanisms.

\section{Competing interests}

The authors declare that they have no competing interests.

\section{Authors' contributions}

STN conceived the idea, did the analyses and wrote the paper. KM participated in the planning of and data collection in the HUNT2 Study. SF, TILN, LFA and KM participated in the analyses, interpreted the results and wrote the paper. All authors discussed and interpreted the findings and contributed to the final paper.

\section{Acknowledgements}

We thank the HUNT Research Centre for providing the data and the women who participated in this study. Nord-Trøndelag Health Study (The HUNT

Study) is a collaboration between HUNT Research Centre (Faculty of Medicine, Norwegian University of Science and Technology NTNU), Nord-Trøndelag County Council and The Norwegian Institute of Public Health. The study was financially supported by the Norwegian University of Science and Technology and by the Central Norway Regional Health Authority. 


\section{Author details}

'Department of Public Health and General Practice, Norwegian University of Science and Technology, PO Box 8904 MTFS, 7491 Trondheim, Norway. 2 Department of Human Movement Science, Norwegian University of Science and Technology, Dragvoll, NO-7491 Trondheim, Norway. ${ }^{3}$ HUNT Research Centre, Norwegian University of Science and Technology, Forskningsveien 2, N-7600 Levanger, Norway. ${ }^{4}$ Institute of Basic Medical Sciences, Postboks 1046, Blindern 0317Oslo, Norway.

Received: 6 September 2011 Accepted: 3 June 2012

Published: 19 June 2012

\section{References}

1. Graham I, Atar D, Borch-Johnsen K, Boysen G, Burell G, Cifkova R, Dallongeville J, De BG, Ebrahim S, Gjelsvik B, et al: European guidelines on cardiovascular disease prevention in clinical practice: full text. Fourth Joint Task Force of the European Society of Cardiology and other societies on cardiovascular disease prevention in clinical practice (constituted by representatives of nine societies and by invited experts). Eur J Cardiovasc Prev Rehabil 2007 14(2):1-113

2. Jonas W, Nissen E, Ransjo-Arvidson AB, Wiklund I, Henriksson P, Uvnas-Moberg K: Short- and long-term decrease of blood pressure in women during breastfeeding. Breastfeed Med 2008, 3:103-109.

3. Qureshi IA, Xi XR, Limbu YR, Bin HY, Chen MI: Hyperlipidaemia during normal pregnancy, parturition and lactation. Ann Acad Med Singapore 1999, 28:217-221.

4. McManus RM, Cunningham I, Watson A, Harker L, Finegood DT: Beta-cell function and visceral fat in lactating women with a history of gestational diabetes. Metabolism 2001, 50:715-719.

5. Ram KT, Bobby P, Hailpern SM, Lo JC, Schocken M, Skurnick J, Santoro N: Duration of lactation is associated with lower prevalence of the metabolic syndrome in midlife-SWAN, the study of women's health across the nation. Am J Obstet Gynecol 2008, 198:268-6.

6. Villegas R, Gao YT, Yang G, Li HL, Elasy T, Zheng W, Shu XO: Duration of breast-feeding and the incidence of type 2 diabetes mellitus in the Shanghai Women's Health Study. Diabetologia 2008, 51:258-266.

7. Stuebe AM, Michels KB, Willett WC, Manson JE, Rexrode K, Rich-Edwards JW: Duration of lactation and incidence of myocardial infarction in middle to late adulthood. Am J Obstet Gynecol 2009, 200:138

8. Lee SY, Kim MT, Jee SH, Yang HP: Does long-term lactation protect premenopausal women against hypertension risk? A Korean women's cohort study. Prev Med 2005, 41:433-438.

9. Liu B, Jorm L, Banks E: Parity, breastfeeding, and the subsequent risk of maternal type 2 diabetes. Diabetes Care 2010, 33:1239-1241.

10. Gunderson EP, Jacobs DR Jr, Chiang V, Lewis CE, Feng J, Quesenberry CP Jr: Sidney S: Duration of lactation and incidence of the metabolic syndrome in women of reproductive age according to gestational diabetes mellitus status: a 20-Year prospective study in CARDIA (Coronary Artery Risk Development in Young Adults). Diabetes 2010, 59:495-504

11. Schwarz EB, Ray RM, Stuebe AM, Allison MA, Ness RB, Freiberg MS, Cauley JA: Duration of lactation and risk factors for maternal cardiovascular disease. Obstet Gynecol 2009, 113:974-982.

12. Schwarz EB, McClure CK, Tepper PG, Thurston R, Janssen I, Matthews KA, Sutton-Tyrrell K: Lactation and maternal measures of subclinical cardiovascular disease. Obstet Gynecol 2010, 115:41-48.

13. Stuebe AM, Schwarz EB, Grewen K, Rich-Edwards JW, Michels KB, Foster EM, Curhan G, Forman J: Duration of lactation and incidence of maternal hypertension: a longitudinal cohort study. Am J Epidemio/ 2011 174:1147-1158.

14. Lande B, Andersen LF, Baerug A, Trygg KU, Lund-Larsen K, Veierod MB, Bjorneboe GE: Infant feeding practices and associated factors in the first six months of life: the Norwegian infant nutrition survey. Acta Paediatr 2003, 92:152-161.

15. Holmen J, Midthjell K, Krüger $\varnothing$, Langhammer A, Holmen TL, Bratberg G, Vatten L, Lund-Larsen PG: The Nord-Trøndelag Health STudy 1995-97 (HUNT 2): Objectives, contents, methods and participation. Norsk Epidemiologi 2003, 13:19-32.
16. Friedewald WT, Levy RI, Fredrickson DS: Estimation of the concentration of low-density lipoprotein cholesterol in plasma, without use of the preparative ultracentrifuge. Clin Chem 1972, 18:499-502.

17. Gunderson EP, Lewis CE, Wei GS, Whitmer RA, Quesenberry CP, Sidney S: Lactation and changes in maternal metabolic risk factors. Obstet Gynecol 2007, 109:729-738.

18. Stuebe AM, Rich-Edwards JW, Willett WC, Manson JE, Michels KB: Duration of lactation and incidence of type 2 diabetes. JAMA 2005, 294:2601-2610.

19. Gunderson EP: Breastfeeding after gestational diabetes pregnancy: subsequent obesity and type 2 diabetes in women and their offspring. Diabetes Care 2007, 30(Suppl 2):S161-S168.

20. McClure CK, Catov J, Ness R, Schwarz EB: Maternal visceral adiposity by consistency of lactation. Matern Child Health J 2012, 16:316-321.

21. Baker JL, Gamborg M, Heitmann BL, Lissner L, Sorensen TI, Rasmussen KM: Breastfeeding reduces postpartum weight retention. Am J Clin Nutr 2008, 88:1543-1551.

22. Lande B, Andersen LF, Veierod MB, Baerug A, Johansson L, Trygg KU, Bjorneboe GE: Breast-feeding at 12 months of age and dietary habits among breast-fed and non-breast-fed infants. Public Health Nutr 2004, 7:495-503.

23. Dennis CL: Breastfeeding initiation and duration: a 1990-2000 literature review. J Obstet Gynecol Neonatal Nurs 2002, 31:12-32.

24. Kim C, Newton KM, Knopp RH: Gestational diabetes and the incidence of type 2 diabetes: a systematic review. Diabetes Care 2002, 25:1862-1868.

25. Jevitt C, Hernandez I, Groer M: Lactation complicated by overweight and obesity: supporting the mother and newborn. J Midwifery Womens Health 2007, 52:606-613.

26. Amir LH, Donath S: A systematic review of maternal obesity and breastfeeding intention, initiation and duration. BMC Pregnancy Childbirth 2007, 7:9.

27. Neubauer SH, Ferris AM, Chase CG, Fanelli J, Thompson CA, Lammi-Keefe CJ, Clark RM, Jensen RG, Bendel RB, Green KW: Delayed lactogenesis in women with insulin-dependent diabetes mellitus. Am J Clin Nutr 1993 58:54-60.

28. Marmot M, Elliot P: Coronary Heart Disease Epidemiology. From aetiology to public health. Oxford: Oxford University Press; 2009.

29. Gunderson EP, Hedderson MM, Chiang V, Crites Y, Walton D, Azevedo RA, Fox G, Elmasian C, Young S, Salvador N, et al: Lactation intensity and postpartum maternal glucose tolerance and insulin resistance in women with recent GDM: the SWIFT cohort. Diabetes Care 2012, 35:50-56

30. Li R, Scanlon KS, Serdula MK: The validity and reliability of maternal recall of breastfeeding practice. Nutr Rev 2005, 63:103-110.

31. Promislow JH, Gladen BC, Sandler DP: Maternal recall of breastfeeding duration by elderly women. Am J Epidemiol 2005, 161:289-296.

32. Langhammer A, Johnsen R, Holmen J, Gulsvik A: Bjermer L. Cigarette smoking gives more respiratory symptoms among women than among men. The Nord-Trondelag Health Study (HUNT). J Epidemiol Community Health 2000, 54:917-922.

33. Lassek WD, Gaulin SJ: Changes in body fat distribution in relation to parity in American women: a covert form of maternal depletion. Am J Phys Anthropol 2006, 131:295-302.

34. Catalano P: The diabetogenic state of maternal metabolism in pregnancy. NeoReviews 2002, 3:165-172

35. MacGillivray I, Rose GA, Rowe B: Blood pressure survey in pregnancy. Clin Sci 1969, 37:395-407.

36. Salameh WA, Mastrogiannis DS: Maternal hyperlipidemia in pregnancy. Clin Obstet Gynecol 1994, 37:66-77.

37. Knopp RH, Bergelin RO, Wahl PW, Walden CE, Chapman M, Irvine S: Population-based lipoprotein lipid reference values for pregnant women compared to nonpregnant women classified by sex hormone usage. Am J Obstet Gynecol 1982, 143:626-637.

38. Ness RB, Harris T, Cobb J, Flegal KM, Kelsey JL, Balanger A, Stunkard AJ, D'Agostino RB: Number of pregnancies and the subsequent risk of cardiovascular disease. N Engl J Med 1993, 328:1528-1533.

39. Skilton MR, Serusclat A, Begg LM, Moulin P, Bonnet F: Parity and carotid atherosclerosis in men and women: insights into the roles of childbearing and child-rearing. Stroke 2009, 40:1152-1157.

40. Stuebe AM, Rich-Edwards JW: The reset hypothesis: lactation and maternal metabolism. Am J Perinatol 2009, 26:81-88. 
41. Butte NF, Wong WW, Hopkinson JM: Energy requirements of lactating women derived from doubly labeled water and milk energy output. J Nutr 2001, 131:53-58.

42. Sichieri R, Field AE, Rich-Edwards J, Willett WC: Prospective assessment of exclusive breastfeeding in relation to weight change in women. Int J Obes Relat Metab Disord 2003, 27:815-820.

43. Dewey KG, Heinig MJ, Nommsen LA: Maternal weight-loss patterns during prolonged lactation. Am J Clin Nutr 1993, 58:162-166.

44. Brewer MM, Bates MR, Vannoy LP: Postpartum changes in maternal weight and body fat depots in lactating vs nonlactating women. Am J Clin Nutr 1989, 49:259-265.

45. Dugdale $A E$, Eaton-Evans J: The effect of lactation and other factors on post-partum changes in body-weight and triceps skinfold thickness. Br J Nutr 1989, 61:149-153.

46. Light KC, Grewen KM, Amico JA, Brownley KA, West SG, Hinderliter AL, Girdler SS: Oxytocinergic activity is linked to lower blood pressure and vascular resistance during stress in postmenopausal women on estrogen replacement. Horm Behav 2005, 47:540-548.

47. Mankad R, Best PJ: Cardiovascular disease in older women: a challenge in diagnosis and treatment. Womens Health (Lond Engl) 2008, 4:449-464.

48. He FJ, MacGregor GA: Effect of modest salt reduction on blood pressure: a meta-analysis of randomized trials. Implications for public health. J Hum Hypertens 2002, 16:761-770.

49. Law MR, Wald NJ, Thompson SG: By how much and how quickly does reduction in serum cholesterol concentration lower risk of ischaemic heart disease? BMJ 1994, 308:367-372.

doi:10.1186/1746-4358-7-8

Cite this article as: Natland et al: Lactation and cardiovascular risk factors in mothers in a population-based study: the HUNT-study.

International Breastfeeding Journal 2012 7:8.

\section{Submit your next manuscript to BioMed Central and take full advantage of:}

- Convenient online submission

- Thorough peer review

- No space constraints or color figure charges

- Immediate publication on acceptance

- Inclusion in PubMed, CAS, Scopus and Google Scholar

- Research which is freely available for redistribution 